\title{
Novel sequence variants and common recurrent polymorphisms of $B R C A 2$ in Sri Lankan breast cancer patients and a family with $B R C A 1$ mutations
}

\author{
SUMADEE DE SILVA ${ }^{1}$, KAMANI H. TENNEKOON ${ }^{1}$, ERIC H. KARUNANAYAKE ${ }^{1}$, WASANTHI DE SILVA ${ }^{1}$, \\ INDRANI AMARASINGHE ${ }^{2}$ and PREETHIKA ANGUNAWELA ${ }^{3}$ \\ ${ }^{1}$ Institute of Biochemistry, Molecular Biology and Biotechnology, University of Colombo, Colombo 03; \\ ${ }^{2}$ National Cancer Institute, Maharagama; ${ }^{3}$ Department of Pathology, Faculty of Medicine, \\ University of Colombo, Colombo 08, Sri Lanka
}

Received June 28, 2011; Accepted August 2, 2011

DOI: $10.3892 /$ etm.2011.337

\begin{abstract}
We previously reported $B R C A 1$ mutations and sequence variants in Sri Lankan breast cancer patients. Mutations and sequence variants of the BRCA2 gene were studied in 149 study participants from the same cohort. There were 55 familial and 54 sporadic breast cancer patients, 20 at-risk individuals and 20 healthy controls. Direct sequencing (exon 11) and sequencing of abnormal bands after screening with single-strand conformation polymorphism (remaining exons) were used to detect mutations and sequence variants. Twenty-three sequence variants were found in the BRCA2 gene. Two novel pathogenic frame-shift additions resulting in a premature stop codon (c.2403 insA/exon 11, c.2667 insT/exon 11) were identified. Possibly pathogenic two novel missense mutations (c.1191 A>C/exon 10, c.5695 A>C/ exon 11) one novel intronic variant (IVS15-21 insTT), four novel silent mutations (c.969 C>T/exon 9, c.1353 C>T/exon 10, c.2766 $\mathrm{A}>\mathrm{C} /$ exon 11 and c.7452 $\mathrm{A}>\mathrm{G} /$ exon 14) and one novel missense mutation (c.971 C>G/exon 9) were observed. One previously reported possibly pathogenic intronic variant (IVS81 G>C) and several previously reported silent mutations, missense mutations, and one 5' UTR polymorphism were detected. Pathogenic and possibly pathogenic mutations were more frequent in the BRCA2 gene among Sri Lankan familial breast cancer patients when compared to our previous findings for the BRCAl gene.
\end{abstract}

\section{Introduction}

Breast cancer is a complex, multifactorial disease with a strong interplay between genetic and environmental

Correspondence to: Dr Kamani H. Tennekoon, Institute of Biochemistry, Molecular Biology and Biotechnology, University of Colombo, 90 Cumaratunga Munidasa Mawatha, Colombo 03, Sri Lanka E-mail:kamani@ibmbb.cmb.ac.lk

Key words: BRCA2, breast cancer factors (1). Worldwide, it is the most common malignancy in women accounting for $23 \%$ of all cancers and the primary cause of death. It is the second most common cancer when both genders are considered together (2). At present, in Sri Lanka, breast cancer in women diagnosed at a median age of 50 years contributes to approximately $25 \%$ of all cancers (3). The age-standardized incidence rate (ASR) of breast cancer per 100,000 women significantly differs between developed and developing countries, and ASR for female breast cancer is 18.4 in Sri Lanka (3-5).

Although several risk factors including family history predispose to breast cancer, the most potent appear to be mutations in the breast cancer susceptibility genes BRCAl (MIM 113705) and BRCA2 (MIM 600185) (6). Even though familial breast cancer accounts for only $5-10 \%$ of all breast cancers, individuals carrying mutations in one of these genes have a 40-80\% chance of developing breast cancer (7). The lifetime risk of developing breast cancer by the age of 70 years is $46-87 \%$ for $B R C A 1$ and $26-84 \%$ for $B R C A 2$ mutation carriers (8-10). The BRCAl gene located on the long arm of chromosome 17 (17q21) consists of 24 exons coding for 1863 amino acids (11). The BRCA2 gene located on chromosome 13 (13q12.3) consists of 27 exons coding for 3418 amino acids (12). Both genes apparently function as tumour-suppressor genes and play a pivotal role in the control of homologous recombination and double-strand break repair in response to DNA damage (13-15).

We recently reported $B R C A 1$ mutations in a cohort of Sri Lankan breast cancer patients (16) but BRCA2 germline mutations have not been previously characterized. Mutations in both genes together account for the majority of families with hereditary susceptibility to breast and ovarian cancer (17). Furthermore, mutations in the central portion of the BRCA2 gene [ovarian cancer cluster region (OCCR)] are reported to be associated with a significantly higher ratio of cases of ovarian:breast cancer in female carriers than the mutations in the $5^{\prime}$ or $3^{\prime}$ region (18). Mutations in the BRCA2 gene in men lead to an increased risk of cancers in the breast, prostate and pancreas (19). 
Table I. Characteristics of the patients selected for the study.

Familial breast cancer $(\mathrm{n}=55)$

Sporadic breast cancer $(n=54)$

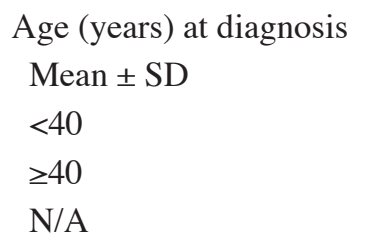

$47.76 \pm 9.55$

15

39

1

0

34 (1st, 13; 2nd, 21)

17 (1st, 4; 2nd, 9; 1st and 2nd both, 4)

3 (1st, 1; 2nd, 0; 1st and 2nd both, 2)

1 (1st and 2 nd )
$47.60 \pm 10.49$

11

41

2

54

0

0

0

0

No. of family members with other cancers ${ }^{\mathrm{a}}$

$\begin{array}{lrr}1 & 16 & 0 \\ 2 & 5 & 0 \\ 3 & 1 & 0 \\ 4 & 1 & 0\end{array}$

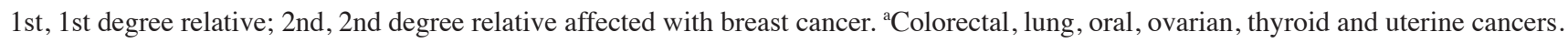

$B R C A 1$ - and BRCA2-associated risks of developing cancer differ in geographical and historically defined groups. Ethnic group-specific mutations showing a high frequency of occurrence are referred to as founder mutations. Identification of a founder mutation is a vital step towards the improvement of genetic screening and counselling. It also facilitates more specific approaches to molecular testing $(7,20)$. In the present study, 109 breast cancer patients, 20 at-risk individuals and 20 healthy controls were screened for BRCA2 mutations. Here, we report novel and previously reported pathogenic and possibly pathogenic mutations, intronic variants and common polymorphisms observed.

\section{Materials and methods}

Study participants. A total of 109 patients ( $\mathrm{n}=55$ with a family history of breast cancer and $n=54$ sporadic breast cancer), 20 at-risk individuals and 20 healthy controls without a personal or family history of any cancer were studied. They were study participants in whom we previously investigated BRCAI mutations, and their characteristics have been previously described (16). The number of patients studied in the present study was slightly lower than that in the BRCAl study. At-risk individuals were limited to members of a family with a history of breast and other cancers where one breast cancer patient and two unaffected family members carry a deleterious $B R C A I$ mutation but included an additional study participant than in the BRCAl study. Characteristics of the study participants are summarised in Table I. Mean age at diagnosis was 47.76 \pm 9.55 and $47.60 \pm 10.49$ years for familial and sporadic breast cancer patients, respectively. Fourteen familial and 10 sporadic breast cancer patients were diagnosed below 40 years of age. Among the familial cases 34, 17 and 3 patients had one, two and three affected family members, respectively. One patient had 4 affected family members. The majority of the patients and controls and all at-risk individuals were ethnically Sinhalese. There were no descendents of Europeans. Ethical approval from the Institution Review Board and written informed consent from the study participants were obtained prior to the study. Socio-demographic and clinical data were obtained from the study participants, and cancer diagnoses were confirmed by reviewing medical reports and pathology reports.

Samples. Genomic DNA was extracted using the protocol described by Miller et al (21) from aliquots of peripheral blood samples that had been stored at $-20^{\circ} \mathrm{C}$.

Primer design and PCR conditions. Nine sets of overlapping primers were designed for the exon 11 coding region and adjacent intronic region of $B R C A 2$ using the website 'Primer3: WWW primer tool' (22). Specific primers for other exons of the $B R C A 2$ gene for PCR amplification were selected from the $\mathrm{BIC}$ primer database.

Polymerase chain reaction (PCR) amplification was performed using each of the 40 primer pairs in a $25-\mu 1$ volume containing $100 \mathrm{ng}$ genomic DNA, 1.0-3.5 mmol/1 $\mathrm{MgCl}_{2}$, 1X PCR buffer [10 mM Tris- $\mathrm{HCl}(\mathrm{pH} 8.3)$ and $50 \mathrm{mM} \mathrm{KCl}$, $2.5 \mathrm{mmol} / \mathrm{l}$ dNTPs (Promega, Madison, WI, USA), 5 pmols of each primer and 0.5 units of Taq polymerases (Promega). The PCR reaction was carried out for 33 cycles, and the thermal regime consisted of an initial denaturation at $94^{\circ} \mathrm{C}$ for $7 \mathrm{~min}$, subsequent denaturation at $94^{\circ} \mathrm{C}$ for $1 \mathrm{~min}$, annealing at the 
Table II. Clearly pathogenic and possibly pathogenic BRCA2 mutations identified.

\begin{tabular}{lccccccccc}
\hline E/I & NT & $\begin{array}{c}\text { Base } \\
\text { change }\end{array}$ & Codon & $\begin{array}{c}\text { AA } \\
\text { change }\end{array}$ & Designation & $\begin{array}{c}\text { Variation } \\
\text { type }\end{array}$ & $\begin{array}{c}\text { BIC } \\
\text { entry }\end{array}$ & $\begin{array}{c}\text { Cases } \\
(\%)\end{array}$ & Pathogenic \\
\hline I-8 & $910-1$ & G $>$ C & Non-coding & - & IVS8-1 G $>$ C & IVS & Yes & $1(0.78)$ & Clearly \\
10 & 1191 & A $>$ C & 321 & Lys $>$ Asn & 1191 A $>$ C & M-UV & No & $4(3.1)$ & Possibly \\
$11^{\text {a }}$ & 2403 & ins A & 726 & Val $>$ Ser & 2403 insA & F & No & $4(4.2)$ & Clearly \\
$11^{\text {a }}$ & 2667 & ins T & 813 & Pro $>$ Ser & 2667 insT & F & No & $1(1.05)$ & Clearly \\
$11^{\text {a }}$ & 5695 & A $>$ C & 1823 & Lys $>$ Gln & 5695 A $>$ C & M-UV & No & $6(6.3)$ & Possibly \\
\hline
\end{tabular}

${ }^{a}$ Exon 11 analysis was carried out only in 95 study participants (55 familial cases, 20 at risk individuals and 20 controls). E/I, exon/intron; F, frame-shift; IVS, intervening sequence/intron; M, missense alteration; UV, unclassified variants.

respective optimal temperature for 1 min and extension at $72^{\circ} \mathrm{C}$ for $2 \mathrm{~min}$ and final extension at $72^{\circ} \mathrm{C}$ for $10 \mathrm{~min}$. The optimal annealing temperature was obtained by optimizing the PCR condition for each primer set for the exons of $B R C A 2$, and this varied from 51 to $66^{\circ} \mathrm{C}$.

\section{Mutation detection}

Single-strand conformation polymorphism. Single-strand conformation polymorphism (SSCP) analysis was performed on all the exons except exon 11 in the familial and sporadic breast cancer patients, at-risk individuals from family F-01 and healthy controls as previously described (16). Equal volumes of the PCR product of the sample and denaturing loading buffer (95\% formamide, $0.05 \%$ xylene cyanol, $0.05 \%$ bromophenol blue) were heated at $95^{\circ} \mathrm{C}$ for $5 \mathrm{~min}$. Denatured DNA samples were separated by $10 \%$ polyacrylamide gel electrophoresis in non-denaturing gel and run at $100 \mathrm{~V}$ for $8-10 \mathrm{~h}$ in $0.5 \mathrm{X}$ TBE at $10-15^{\circ} \mathrm{C}$. Separated DNA fragments were visualized by silver staining (23). Samples which showed abnormal migration patterns on SSCP were reconfirmed by performing a second PCR reaction followed by a second SSCP run.

DNA sequencing. Samples to be sequenced were PCR amplified and the products were purified using $\mathrm{GFX}^{\mathrm{TM}}$ PCR DNA and Gel Band Purification (GE Healthcare Bio-Sciences Corp., Piscataway, NJ, USA). Purified PCR products were directly sequenced using the commercially available DYEnamic ${ }^{\mathrm{TM}}$ ET Dye Terminator kit (GE Healthcare) and MegaBACE 1000 automated DNA sequencer. Mutations and sequence variants detected were reconfirmed by performing a second PCR and direct sequencing. Exon 11 was analyzed by direct sequencing. This analysis was limited to 55 patients with a family history, 20 at-risk individuals and 20 healthy controls. Direct sequencing was also carried out for the samples showing abnormal banding patterns during SSCP screening and for some representative samples not showing any abnormal banding patterns to confirm the mutations and sequence variants.

\section{Results}

This is the first report on $B R C A 2$ mutations and polymorphisms in Sri Lankan breast cancer patients in whom BRCAl muta- tions and sequence variants have been characterized recently (16). A total of 149 including 109 patients were studied, and twenty-three sequence variants were identified.

Clearly and possibly pathogenic mutations are shown in Table II. Two novel frame-shift mutations, c.2403 insA and c.2667 insT in exon 11, and two novel possibly pathogenic mutations, c.1191 $\mathrm{A}>\mathrm{C}$ in exon 10 and c.5695 $\mathrm{A}>\mathrm{C}$ in exon 11, and previously reported possibly pathogenic intronic variant, IVS8-1 G>C in intron 8, were detected. Sequence variants with unknown significance and polymorphisms are shown in Table III. Twelve previously reported polymorphisms in the exon 2 untranslated region (5'UTR) and in exon 10, 11 and 14 were identified (Table III). Six novel polymorphisms in exons 9, 10, 11, 14 and IVS15-21 insTT in intron 15 were observed.

c.2403 insA in exon 11 (codon 726), a novel frame shift insertion, created a stop codon at codon 750 of the BRCA2 protein in four unrelated patients with a family history of breast cancer. All four of them were Sinhalese. Three of them, diagnosed with breast cancer at an early age $(35,38$, 47 years) had one affected second degree relative each. The fourth patient diagnosed at the age of 51 years is unmarried and has a sister affected with breast cancer. Recurrence of the disease after 10 years of initial diagnosis was reported in one. Mutation c.2667 insT in exon 11 which is also novel created a stop codon at codon 825 in the BRCA2 protein. It was found in one patient diagnosed with breast cancer at 53 years of age having two affected first degree relatives.

Possibly pathogenic novel missense alteration c.5695 A>C (exon 11) was found in six study participants from family F-01. The pedigree of this family is shown in Fig. 1. Pedigree numbers and sequence variants found in this family are shown in Table IV. This family consists of 8 siblings in the 2 nd generation of which 4 are deceased, one each from breast (II. 8 at the age of 38 years), uterine (II.10 at the age of 42 years) and oral (II.6 at the age of 60 years) cancers. The possibly pathogenic mutation (c.5695 A>C in exon 11) was found in 3 members of the 3rd generation (III.3, III.6, III.19) and 3 members of the 4th generation (IV.1, IV.2, IV.5). One member (III.19) carrying this mutation also has a deleterious mutation in exon 21 of BRCAl (c.5405 delG) (16). Another (IV.5) was diagnosed with salivary gland cancer at 13 years of age and her paternal grandfather (II.6) and maternal grandmother (II.8) had died of oral and breast cancer, respectively. Her mother (III.9) carries 


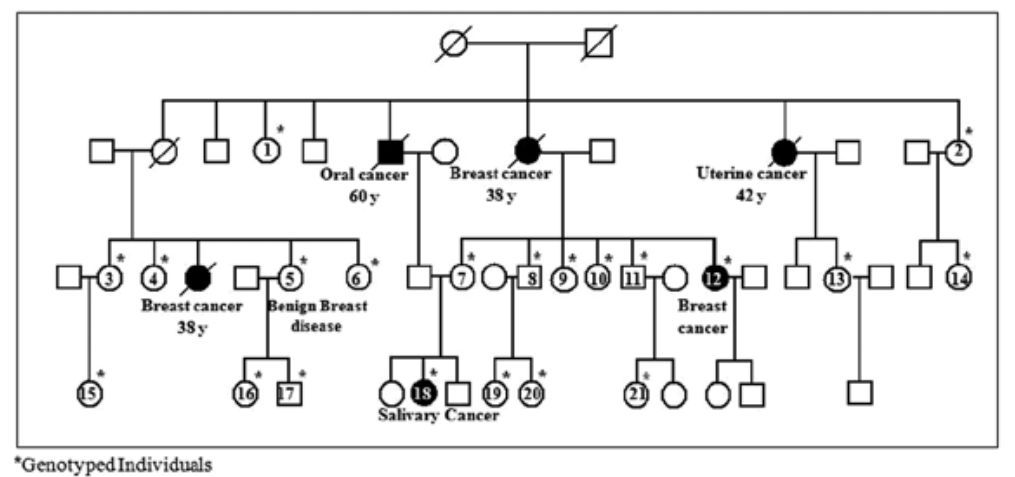

Figure 1. Pedigree of family F-01. The age of onset of the disease for members affected with breast cancer, other cancers and benign breast disease are indicated. Mutations and polymorphisms in BRCA2 as related to family members are provided in Table IV.

Table III. Sequence variants with unknown significance and known polymorphisms of the $B R C A 2$ gene identified.

\begin{tabular}{|c|c|c|c|c|c|c|c|c|c|c|c|}
\hline \multirow[t]{2}{*}{$\mathrm{E} / \mathrm{I}$} & \multirow[t]{2}{*}{ NT } & \multirow[t]{2}{*}{ Base } & \multirow[t]{2}{*}{$\begin{array}{l}\text { Codon } \\
\text { change }\end{array}$} & \multirow[t]{2}{*}{$\begin{array}{c}\text { AA } \\
\text { change }\end{array}$} & \multirow[t]{2}{*}{ Designation } & \multirow[t]{2}{*}{$\begin{array}{l}\text { Variation } \\
\text { type }\end{array}$} & \multirow[t]{2}{*}{$\begin{array}{l}\text { BIC } \\
\text { Entry }\end{array}$} & \multicolumn{4}{|c|}{$\begin{array}{l}\text { No. of cases carrying } \\
\text { the sequence variant }\end{array}$} \\
\hline & & & & & & & & $\mathrm{F}(\mathrm{n}=55)$ & $S(n=54)$ & $\mathrm{R}(\mathrm{n}=20)$ & $C(n=20)$ \\
\hline 2 & 203 & $\mathrm{G}>\mathrm{A}$ & - & - & $203 \mathrm{G}>\mathrm{A}$ & 5'UTR & Yes & 36 & 35 & 12 & 2 \\
\hline 9 & 969 & $\mathrm{C}>\mathrm{T}$ & 247 & Iso $>$ Iso & $969 \mathrm{C}>\mathrm{T}$ & Silent-P & No & 1 & 0 & 0 & 0 \\
\hline 9 & 971 & $\mathrm{C}>\mathrm{G}$ & 247 & Ala>Gly & $971 \mathrm{C}>\mathrm{G}$ & M-P & No & 1 & 0 & 0 & 0 \\
\hline 10 & 1093 & $\mathrm{~A}>\mathrm{C}$ & 289 & Asn $>$ His & $1093 \mathrm{~A}>C$ & M-P & Yes & 6 & 3 & 3 & 0 \\
\hline 10 & 1342 & $\mathrm{~A}>\mathrm{C}$ & 372 & Asn $>$ His & $1342 \mathrm{~A}>\mathrm{C}$ & M-P & Yes & 30 & 13 & 16 & 5 \\
\hline 10 & 1352 & $\mathrm{C}>\mathrm{T}$ & 375 & Pro $>$ Leu & $1352 \mathrm{C}>\mathrm{T}$ & M-P & Yes & 4 & 0 & 1 & 0 \\
\hline 10 & 1353 & $\mathrm{C}>\mathrm{T}$ & 375 & Pro $>$ Pro & $1353 \mathrm{C}>\mathrm{T}$ & Silent-P & No & 1 & 0 & 2 & 0 \\
\hline 10 & 1593 & $\mathrm{~A}>\mathrm{G}$ & 455 & Ser $>$ Ser & $1593 \mathrm{~A}>\mathrm{G}$ & Silent-P & Yes & 1 & 0 & 4 & 0 \\
\hline $11^{\mathrm{a}}$ & 2457 & $\mathrm{~T}>\mathrm{C}$ & 743 & His $>$ His & $2457 \mathrm{~T}>\mathrm{C}$ & Silent-P & Yes & 0 & - & 1 & 0 \\
\hline $11^{\mathrm{a}}$ & 2766 & $A>C$ & 846 & Ser $>$ Ser & $2766 \mathrm{~A}>\mathrm{C}$ & Silent-P & No & 0 & - & 1 & 0 \\
\hline $11^{\mathrm{a}}$ & 3538 & $\mathrm{~A}>\mathrm{C}$ & 1103 & Thr $>$ Pro & $3538 \mathrm{~A}>\mathrm{C}$ & M-P & Yes & 0 & - & 1 & 0 \\
\hline $11^{\mathrm{a}}$ & 3624 & $\mathrm{~A}>\mathrm{G}$ & 1132 & Lys $>$ Lys & $3624 \mathrm{~A}>\mathrm{G}$ & Silent-P & Yes & 0 & - & 6 & 1 \\
\hline $11^{\mathrm{a}}$ & 4035 & $\mathrm{~T}>\mathrm{C}$ & 1269 & Val $>$ Val & $4035 \mathrm{~T}>\mathrm{C}$ & Silent-P & Yes & 0 & - & 1 & 0 \\
\hline $11^{\mathrm{a}}$ & 4791 & $\mathrm{~A}>\mathrm{G}$ & 1521 & Leu $>$ Leu & $4791 \mathrm{~A}>\mathrm{G}$ & Silent-P & Yes & 50 & - & 20 & 17 \\
\hline $11^{\mathrm{a}}$ & 6741 & $\mathrm{G}>\mathrm{C}$ & 2171 & Val $>$ Val & $6741 \mathrm{G}>\mathrm{C}$ & Silent-P & Yes & 47 & - & 20 & 18 \\
\hline 14 & 7452 & $\mathrm{~A}>\mathrm{G}$ & 2408 & Pro $>$ Pro & $7452 \mathrm{~A}>\mathrm{G}$ & Silent-P & No & 15 & 13 & 20 & 0 \\
\hline 14 & 7470 & $\mathrm{~A}>\mathrm{G}$ & 2414 & Ser $>$ Ser & $7470 \mathrm{~A}>\mathrm{G}$ & Silent-P & Yes & 0 & 0 & 1 & 0 \\
\hline $\mathrm{I}-15$ & $7845-21$ & insTT & $\mathrm{N}-\mathrm{C}$ & - & IVS15-21 insTT & UV & No & 1 & 0 & 0 & 0 \\
\hline
\end{tabular}

E/I, exon/intron; F, familial breast cancer patients; S, sporadic breast cancer patients; R, at risk individuals; C, healthy controls. M, missense alteration; P, polymorphism; UV, unclassified variants. ${ }^{a}$ Exon 11 analysis was carried out only in 95 study participants (55 familial breast cancer patients, 20 at-risk individuals and 20 controls).

a novel possibly pathogenic missense mutation, c.1191 $\mathrm{A}>\mathrm{C}$ in exon 10. The same mutation was also found in 2 other at-risk individuals from the F-01 family (III.02, III.13) and in another familial breast cancer patient from a different family diagnosed at the age of 49 years and having one first and one second degree relative affected.

A previously reported possibly pathogenic intronic variant, IVS8-1 G>C in intron 8, was detected in one patient with breast cancer and ovarian cancer both occurring at the age of 46 years. She also has co-existing novel silent (c.969 C>T) and missense (c.971 C>G) mutations in exon 9. This patient has two second degree relatives affected with breast cancer.

Novel unclassified variant IVS15-21 insTT in intron 15 was found in one patient diagnosed at 43 years of age whose mother also had breast cancer. Analysis of the IVS15-21 insTT intronic variant using Human Splicing Finder version 2.4 


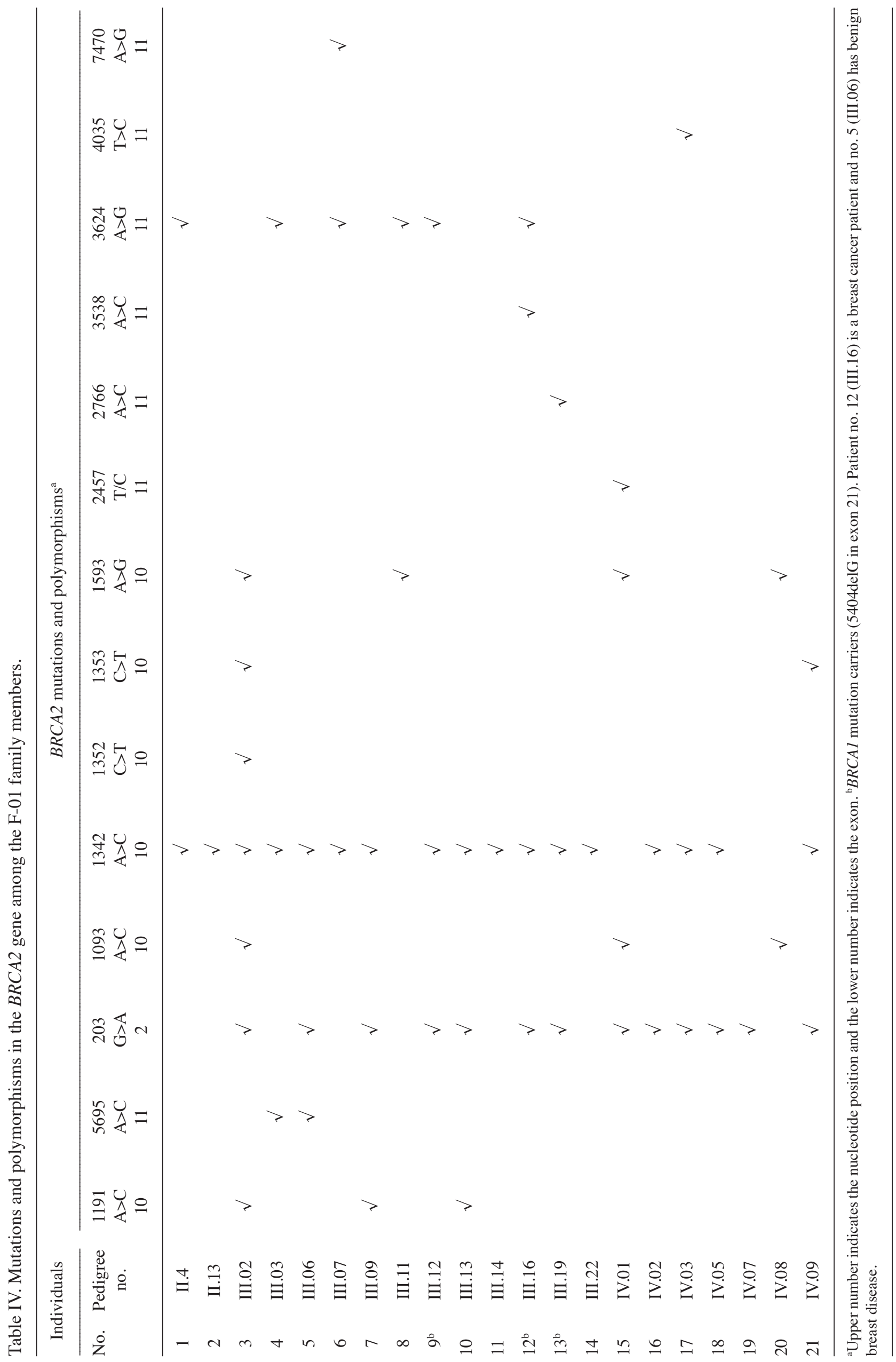


showed that the acceptor motif of the exon 16 (at -12 region) is located several bases away (downstream) from the detected variant (24).

We found four previously reported (c.1093 $\mathrm{A}>\mathrm{C}$, c.1342 A>C (p.N372H), c.1352 C>T, c.1593 A>G) and one novel (c.1353 $\mathrm{C}>\mathrm{T}$ ) polymorphism in exon 10. Missense mutation c.1093 $\mathrm{A}>\mathrm{C}$ was identified in six familial and three sporadic breast cancer patients, 3 at-risk individuals but in none of the healthy controls. c.1342 A>C (p.N372H) was the most prevalent polymorphism, and the prevalence was significantly higher among familial breast cancer patients and at-risk individuals (80\%) than among sporadic breast cancer patients (24\%) and healthy controls (25\%). Missense mutation c.1352 $\mathrm{C}>\mathrm{T}$ was detected in four familial breast cancer patients and 1 at-risk individual, silent mutation c.1593 A>G in one familial breast cancer patient and 4 at-risk individuals and novel silent mutation c.1353 $\mathrm{C}>\mathrm{T}$ in one familial breast cancer patient and 2 at-risk individuals. These three mutations were not found in sporadic breast cancer patients or healthy controls. All five polymorphisms in exon 10 co-existed in one at-risk individual from the F-01 family (III.02).

In addition to the clearly and possibly pathogenic mutations, we detected seven other sequence variants in exon 11. These were three reported silent mutations (c.2457 T $>\mathrm{C}$ in one at-risk individual, c.3624 $\mathrm{A}>\mathrm{C}$ in 6 at-risk individuals and one healthy control and c.4035 $\mathrm{T}>\mathrm{C}$ in 1 at-risk individual), one novel silent mutation (c.2766 $\mathrm{A}>\mathrm{C}$ in 1 at-risk individual), a reported missense mutation (c.3538 $\mathrm{A}>\mathrm{C}$ in one familial breast cancer patient) and two reported common polymorphisms (c.4791 A>G and c.6741 G>C). Prevalence of the two common polymorphisms did not significantly differ between familial breast cancer patients, at-risk individuals and healthy controls and these were not studied in sporadic breast cancer patients.

We found the previously reported polymorphism c. $203 \mathrm{G}>\mathrm{A}$ in exon 2 in $>60 \%$ of the familial and sporadic breast cancer patients and at-risk individuals but at a lower prevalence $(16.5 \%)$ among the healthy controls. A novel common polymorphism c.7452 $\mathrm{A}>\mathrm{G}$ in exon 14 was also found in the familial and sporadic breast cancer patients and at-risk individuals but not in any healthy controls. One at-risk individual also carried the reported silent mutation c.7470 $\mathrm{A}>\mathrm{G}$ in exon 14 in addition to this polymorphism. The most common four polymorphisms, c.203 G>A in exon 2, c.1342 A>C in exon 10, and c.4791 $\mathrm{A}>\mathrm{G}$ and c.6741 $\mathrm{G}>\mathrm{C}$ in exon 11, identified in the present study co-existed in several familial patients, at-risk individuals and healthy controls.

\section{Discussion}

After screening a predominantly Sinhalese cohort of familial and sporadic breast cancer patients, at-risk individuals from a family carrying a deleterious $B R C A 1$ mutation and healthy controls, we identified 23 sequence variants in the $B R C A 2$ gene. Two novel pathogenic frame-shift mutations resulting in a premature stop codon in exon 11 and two novel possibly pathogenic mutations one each in exon 10 and 11 and a previously reported pathogenic variant in intron 8 were detected. One novel intronic variant in intron 15 and five novel polymorphisms were observed, two in exon 9 and one each in exons 10 , 11 and 14 . Twelve previously reported polymorphisms were identified, one in the exon 2 untranslated region (5'UTR), four in exon 10, six in exon 11 and one in exon 14.

The two clearly pathogenic mutations identified in the present study (c.2403 insA and c.2667 insT) are frame-shift insertions in exon 11 leading to a premature stop codon and thus resulting in a truncated protein. Of these, c. 2403 ins A occurred in four unrelated familial breast cancer patients of Sinhalese ethnicity indicating that it is likely be a common mutation among familial breast cancer patients in this ethnic group. The number of study participants from other ethnic groups was small, thus one cannot exclude the presence of this mutation in other ethnic groups in Sri Lanka. The other deleterious mutation was found only in one patient.

Mutation c.5695 A $>\mathrm{C}$ found in several members of the F-01 family is located in the sixth BRC repeat (BRC6 repeat) out of the eight BRC repeats encoded by exon 11. The BRC repeats mediate the binding of DNA repair protein Rad51 (25). DNA recombinase RAD51 and BRCA2 protein complex is crucial for the repair of double-strand DNA breaks (26). As this mutation alters lysine (basic polar amino acid) at codon 1823 to glutamine (neutral polar amino acid) it may change conformation of the protein rendering pathogenicity. One at-risk individual found to have this mutation was affected with salivary cancer, diagnosed at the age of 13 years and another was diagnosed with a benign breast tumour at the age of 32 years. The remaining four members carrying this mutation are, at present, free from benign or malignant breast disease or any other cancer despite one of them also carrying a deleterious BRCAl mutation.

Novel missense mutation c.1191 $\mathrm{A}>\mathrm{C}$ in exon 10 found in one familial breast cancer patient and 3 at-risk individuals in the present study, alters amino acid lysine (basic polar amino acid) to asparagine (neutral polar amino acid) at codon 321 . This too can be functionally significant, as it may affect the conformation of the protein.

Nearly 23 and $6.5 \%$ of unclassified variants in BRCAl and $B R C A 2$, respectively, are located in intronic sequences but only few studies have been carried out to identify whether these variants affecting RNA splicing are involved in the pathogenicity of breast cancer (27). According to the BIC database, the intronic variant IVS8-1 G>C located at the splice-site of the intron is clinically important (28). To date, none of the Asian countries have reported this mutation although this has been reported in Western Europe. In exon 9, novel missense mutation c.971 $\mathrm{C}>\mathrm{G}$ alters amino acid alanine (nonpolar aliphatic) to glycine (nonpolar aliphatic) at codon 247. This co-existed with the novel silent mutation c.969 $\mathrm{C}>\mathrm{T}$ in the same patient, and both these sequence variants are unlikely to be of clinical importance. However, the patient who carries these mutations has a previously reported possibly pathogenic intronic variant, IVS8-1 G>C in intron 8 .

Only ten intronic variations have been identified in intron 15 and none of the Asian countries have reported variants in this intron (28). In the present study, we found a novel unclassified variant, IVS15-2 1insTT in intron 15, in one familial breast cancer patient. However, results from the bioinformatic analysis using Human Splicing Finder version 2.4 did not indicate this variant to be pathogenic (24).

One novel and four previously reported polymorphisms were found in exon 10. Missense polymorphism c.1342 A>C 
(BRCA2 p.N372H) occurred more frequently in the familial breast cancer patients and at-risk individuals from family F-01 when compared to the sporadic breast cancer patients and healthy controls suggesting a predisposition to familial breast cancer in its presence. This polymorphism results in non-conservative amino acid substitution [asparagine $(\mathrm{N})$ to histidine $(\mathrm{H})$ ], hence may affect the structure and function of the BRCA2 protein. $\mathrm{N} 372 \mathrm{H}$ locates within a region of BRCA2 (residues 290-453) that has been shown to interact with a transcriptional co-activator protein, $\mathrm{P} / \mathrm{CAF}$, which possesses histone acetyltransferase activity (29). The HH genotype of the $\mathrm{N} 372 \mathrm{H}$ polymorphism in the BRCA2 gene was reported to be associated with a 1.3-fold increased risk of breast cancer in a combined analysis of British, German and Finnish women (30) and in Australian women (31) but others have failed to find a significant effect in older Caucasian women (32). The $\mathrm{N} 372 \mathrm{H}$ polymorphism had an allele frequency of 0.45 in the present study, which was higher than the average frequency of 0.26 reported in British, German and Finnish populations (30). This polymorphism was also reported in a Malaysian population among Malay, Chinese and Indian ethnic groups (33). A more recent meta-analysis failed to show an effect of this polymorphism on breast cancer even when a subgroup analysis by ethnicity was carried out but showed an effect in population-based studies (34). These authors have suggested the $B R C A 2$ p.N372H allele as a low-penetrant risk factor for developing breast cancer.

Missense mutation c.1093 A >C found in six familial breast cancer patients with a strong family history of breast cancer and 3 at-risk individuals has also been reported in studies in Denmark and two Asian countries, Japan (35) and Malaysia (33). Two patients had mothers, three patients had maternal aunts and two patients had maternal grandmothers affected with breast cancer. Apart from that, there were two paternal relations of these patients affected with breast cancer. The c.1593 A>G polymorphism detected in one familial breast cancer patient and 4 at-risk individuals has been reported from Western countries (28) and from Asia $(33,35,36)$. Co-existence of all five polymorphisms identified in exon 10 observed in one at-risk individual does not appear to have been previously reported.

In exon 11, we identified two pathogenic mutations and one possibly pathogenic mutation described above and seven other sequence variants. Of the latter, silent mutations, c. $2457 \mathrm{~T}>\mathrm{C}$ and c.4035 T>C, have been reported in Europe and Malaysia. The missense mutation c.3538 $\mathrm{A}>\mathrm{C}$ detected in a familial breast cancer patient carrying a deleterious BRCAl mutation, alters threonine (hydrophilic polar uncharged) to proline (aliphatic nonpolar) which may be significant for protein folding or binding. However, according to the BIC database this transition effect is recorded as 'unknown'. This variant was reported in Western European communities (28). The allele frequency of c.3624 A>G in exon 11 was much less than what was reported in a European population (allele frequency of 0.08 vs. 0.31). c.4791 $\mathrm{A}>\mathrm{G}$ and c.6741 $\mathrm{G}>\mathrm{C}$ in exon 11 showed a very high allele frequency of 0.86 in the Sri Lankan population whereas according to the BIC database these polymorphisms were recorded only in Africa.

Reported silent mutation c.7470 $\mathrm{A}>\mathrm{G}$ in exon 14 found in one at-risk individual has been reported in several non-Asian (28) and Asian countries $(33,35,36)$. The novel common poly- morphism, c.7452 A>G in exon 14, had an allele frequency of 0.2 but allele frequencies did not significantly differ between study groups.

The frequency of the common polymorphisms differed from those reported for other populations (28). Common polymorphism c. $203 \mathrm{G}>\mathrm{A}$ in exon 2 had an allele frequency of 0.39 in the present study whereas a frequency of 0.25 was reported in predominantly European populations. The four most common polymorphisms co-existed in several familial breast cancer patients and at-risk individuals. Co-existence of these four polymorphisms has not been reported previously, but the presence of c. $203 \mathrm{G}>\mathrm{A}$ in exon 2, c.1342 $\mathrm{A}>\mathrm{C}$ in exon 10 and c.3624 $\mathrm{A}>\mathrm{G}$ in exon 11 has been reported in the Spanish population (28).

The prevalence of clearly pathogenic BRCA2 mutations was $11 \%(6 / 55)$ and, clearly and possibly pathogenic $B R C A 2$ mutations was $12.73 \%$ (7/55) among the familial breast cancer patients. Thus when compared to our previous observation of a prevalence of $6.25 \%$ for BRCA1 mutations (16), BRCA2 mutations appear to be more frequent in Sri Lankan familial breast cancer patients.

In Sri Lanka, approximately $19 \%$ of female breast cancers are diagnosed in women below 50 years of age suggesting a significant genetic susceptibility. However, genetic screening programmes are not in place due to the lack of data on mutations associated with breast cancer for the Sri Lankan population and high cost. We identified two pathogenic and three possibly pathogenic mutations in the BRCA2 gene in familial breast cancer. Of these, c.2403 insA in exon 11, the pathogenic mutation which occurred in 4 out of 51 unrelated Sinhalese patients, is likely to be useful in screening programmes.

\section{Acknowledgements}

We thank the director and staff of the National Cancer Institute, Maharagama, Sri Lanka for their cooperation, Dr Nalinda Silva for assistance with sample collection, Dr Mohamed H. Ziard for assistance with sample collection from the F-01 family. This study was supported by the Sida/Secretariat for Research Cooperation Grant for Molecular Biology and Biotechnology awarded to E.H.K. and K.H.T. and constituted partly to the PhD programme of S.deS.

\section{References}

1. Martin AM, Blackwood MA, Antin-Ozerkis D, et al: Germline mutations in BRCA1 and BRCA2 in breast-ovarian families from a breast cancer risk evaluation clinic. J Clin Oncol 19: 2247-2253, 2001.

2. Parkin DM, Bray F, Ferlay J and Pisani P: Global cancer statistics, 2002. CA Cancer J Clin 55: 74-108, 2005.

3. Cancer Incidence Data: Sri Lanka Year 2001-2005. Cancer Registry, National Cancer Control Programme, Colombo 5, Sri Lanka, 2009.

4. Parkin DM, Whelan SL, Ferlay J, Teppo L and Thomas DB (eds): Cancer Incidence in Five Continents, Vol. VIII. IARC Scientific Publications no. 143, IARC, Lyon, 1997.

5. Liede A and Narod SA: Hereditary breast and ovarian cancer in Asia: genetic epidemiology of $B R C A 1$ and $B R C A 2$. Hum Mutat 20: 413-424, 2002.

6. Newman B, Austin MA,Lee M and King MC: Inheritance of human breast cancer: evidence for autosomal dominant transmission in high risk families. Proc Natl Acad Sci USA 85: 3044-3048, 1988.

7. Fackenthal JD and Olopade OI: Breast cancer risk associated with $B R C A 1$ and $B R C A 2$ in diverse populations. Nat Rev Cancer 7: 937-948, 2007. 
8. Satagopan JM, Offit K, Foulkes W, et al: The lifetime risks of breast cancer in Ashkenazi Jewish carriers of $B R C A 1$ and $B R C A 2$ mutations. Cancer Epidemiol Biomarkers Prev 10: 467-473, 2001.

9. Antoniou A, Pharoah PDP, Narod S, et al: Average risks of breast and ovarian cancer associated with $B R C A 1$ or BRCA2 mutations detected in case series unselected for family history: a combined analysis of 22 studies. Am J Hum Genet 72: 1117-1130, 2003.

10. Lahad EL and Friedman E: Cancer risks among BRCAl and BRCA2 mutation carriers. Br J Cancer 96: 11-15, 2007.

11. Hall JM, Lee MK, Newman B, Morrow JE, Anderson LA, Huey B and King MC: Linkage of early-onset familial breast cancer to chromosome 17q21. Science 250: 1684-1689, 1990.

12. Wooster R, Neuhausen SL, Mangion J, et al: Localization of a breast cancer susceptibility gene, $B R C A 2$, to chromosome 13q12-13. Science 265: 2088-2090, 1994.

13. Narod SA and Foulkes WD: BRCA1 and BRCA2: 1994 and beyond. Nat Rev Cancer 4: 665-676, 2004.

14. Scully R and Livingston DM: In search of the tumour-suppressor function of BRCAI and BRCA2. Nature 408: 429-432, 2000.

15. Venkitaraman AR: Cancer susceptibility and the functions of BRCA1 and BRCA2. Cell 108: 171-182, 2002.

16. De Silva W, Karunanayake EH, Tennekoon KH, Allen M, Amarasinghe I, Angunawala P and Ziard MH: Novel sequence variants and a high frequency of recurrent polymorphisms in $B R C A 1$ gene in Sri Lankan breast cancer patients and at risk individuals. BMC Cancer 8: 214, 2008.

17. Ford D, Easton DF, Stratton M, et al: Genetic heterogeneity and penetrance analysis of the $B R C A 1$ and $B R C A 2$ genes in breast cancer families. The Breast Cancer Linkage Consortium. Am J Hum Genet 62: 676-689, 1998.

18. Thompson D and Easton D: Variation in cancer risks, by mutation position, in BRCA2 mutation carriers. Am J Hum Genet 68 410-419, 2001

19. Liede A, Karlan BY and Narod SA: Cancer risks for male carriers of germline mutations in $B R C A 1$ and $B R C A 2$ : a review of the literature. J Clin Oncol 22: 735-742, 2004.

20. Ferla R, Calo V, Cascio S, et al: Founder mutations in BRCAI and BRCA2 genes. Ann Oncol 18 (Supp 6): S93-S98, 2007.

21. Miller SA, Dykes DD and Poleskey HF: A simple salting out procedure for extracting DNA from human nucleated cells. Nucleic Acids Res 16: 1215, 1988.

22. Rozen S and Skaletsky HJ: Primer3, 1996. Code available at http:// www-genome.wi.mit.edu/genome_software/other/primer3.html.

23. Wallace AJ: SSCP/Heteroduplex analysis. In: PCR Mutation Detection Protocols. Vol 187. Theophilus BDM and Rapley R (eds). Humana Press, Totowa, New Jersey, pp151-163, 2002.
24. Desmet FO, Hamroun D, Lalande M, Collod-Béroud G, Claustres M and Béroud C: Human Splicing Finder: an online bioinformatics tool to predict splicing signals. Nucleic Acid Res 37: e67, 2009

25. Bork $\mathrm{P}, \mathrm{Blomberg} \mathrm{N}$ and Nilges $\mathrm{M}$ : Internal repeats in BRCA2 protein sequence. Nat Genet 13: 22-23, 1996.

26. Lord CJ and Ashworth A: RAD51, BRCA2 and DNA repair: a partial resolution. Nat Struct Mol Biol 14: 461-462, 2007.

27. Vreeswijk MPG, Kraan JN, van der Klift HM, et al: Intronic variants in $B R C A 1$ and $B R C A 2$ that affect RNA splicing can be reliably selected by splice-site prediction programs. Hum Mutat 30: 107-114, 2009.

28. Breast Cancer Information Core (BIC) Database. Available at: http://research.nhgri.nih.gov/bic/. Last modified: Wednesday, 29 September 2010

29. Fuks F, Milner J and Kouzarides T: $B R C A 2$ associates with acetyltransferase activity when bound to P/CAF. Oncogene 17: 2351-2354, 1998

30. Healey CS, Dunning AM, Teare MD, et al: A common variant in $B R C A 2$ is associated with both breast cancer risk and prenatal viability. Nat Genet 26: 362-364, 2000.

31. Spurdle AB, Hopperm JL, Chen X, et al: The BRCA2 $372 \mathrm{HH}$ genotype is associated with risk of breast cancer in Australian women under age 60 years. Cancer Epidemiol Biomarkers Prev 11: 413-416, 2002

32. Cox DG, Hankinson SE and Hunter DJ: No association between $B R C A 2 \mathrm{~N} 372 \mathrm{H}$ and breast cancer risk. Cancer Epidemiol Biomarkers Prev 14: 1353-1354, 2005.

33. Toh GT, Kang P, Lee SSW, et al: BRCA1 and BRCA2 germline mutations in Malaysian women with early onset breast cancer without a family history. PLoS One 3: e2024, 2008.

34. Qiu LX, Yao L, Xue K, et al: BRCA2 N372H polymorphism and breast cancer susceptibility: a meta-analysis involving 44,903 study participants. Breast Cancer Res Treat 123: 487-490, 2010.

35. Ikeda N, Miyoshi Y, Yoned K, Shiba E, Sekihara Y, Kinoshita M and Noguchi S: Frequency of BRCAI and BRCA2 germline mutations in Japanese breast cancer families. Int J Cancer 91: 83-88, 2001.

36. Saxena S, Chakraborthy A, Kaushal M, et al: Contribution of germline $B R C A 1$ and $B R C A 2$ sequence alterations to breast cancer in Northern India. BMC Med Genet 7: 75, 2006. 